\title{
Combined effect of artificial aging and fatigue on the mechanical, structural, and morphological properties of polystyrene
}

\author{
Karollyne Monsores ${ }^{1}$, Anderson Silva ${ }^{1}$, Suzane Oliveira ${ }^{1}$, Ricardo Weber ${ }^{1}$, Paulo Feliciano \\ Filho $^{2}$, Larissa Simão ${ }^{3}$, Eduardo de Carvalho $^{3}$, and Sergio Monteiro ${ }^{1}$ \\ ${ }^{1}$ Instituto Militar de Engenharia \\ ${ }^{2}$ Instituto Federal do Rio de Janeiro \\ ${ }^{3}$ Universidade Estadual do Norte Fluminense
}

October 6, 2020

\begin{abstract}
The mechanical, structural, and morphological properties of polystyrene (PS) under fatigue combined with accelerated aging were investigated. The results revealed that under the condition of fatigue (tension-tension) combined with UV-B exposure, in the periods of 336 and $575 \mathrm{~h}$, the mechanical resistance presented is lower when compared to PS subjected to only fatigue. The modifications produced by the irradiation were evaluated by physical-chemical tests, which resulted in changes in the properties of the degraded materials, such as reduced molecular mass due to chain cleavage and increased crystallinity. The predominant failure mechanism in mechanically fractured specimens was also influenced by irradiation, so that the hardening of the surface layer was characterized by Vickers microhardness.
\end{abstract}

Combined effect of artificial aging and fatigue on the mechanical, structural, and morphological properties of polystyrene

Karollyne Gomes de Castro Monsores ${ }^{1}$, Anderson Oliveira da Silva ${ }^{1}$, Suzane de Sant' Ana Oliveira ${ }^{1}$, Ricardo Pondé Weber ${ }^{1}$, Paulo Feliciano Filho ${ }^{2}$, Larissa Gomes Simão ${ }^{3}$, Eduardo Atem de Carvalho ${ }^{3,}{ }^{*}$, Sergio Neves Monteiro ${ }^{1}$.

${ }^{1}$ Military Institute of Engineering - IME

Department of Materials Science, Praça General Tibúrcio 80, URCA, 22290-270, Rio de Janeiro, RJ, Brazil.

${ }^{2}$ Federal Institute of Education, Science and Technology of Rio de Janeiro - IFRJ

Rio de Janeiro, RJ, Brazil.

${ }^{3}$ Northern Fluminense State University - UENF

Advanced Materials Lab, Av. Alberto Lamego, Horto, 28013-602 - Campos dos Goytacazes, RJ, Brazil

* eatem@uenf.br

*Corresponding author

Abstract: The mechanical, structural, and morphological properties of polystyrene (PS) under fatigue combined with accelerated aging were investigated. The results revealed that under the condition of fatigue (tension-tension) combined with UV-B exposure, in the periods of 336 and $575 \mathrm{~h}$, the mechanical resistance presented is lower when compared to PS subjected to only fatigue. The modifications produced by the irradiation were evaluated by physical-chemical tests, which resulted in changes in the properties of the 
degraded materials, such as reduced molecular mass due to chain cleavage and increased crystallinity. The predominant failure mechanism in mechanically fractured specimens was also influenced by irradiation, so that the hardening of the surface layer was characterized by Vickers microhardness.

Keywords: Fatigue Life, Thermo Mechanical Fatigue, Polymer, Thermal Aging Degradation.

\section{Nomenclature}

$\mathrm{A}_{0}$ - Surface area $\left(\mathrm{cm}^{2}\right)$

$\mathrm{I}_{\mathrm{e}}$ - Incident energy $\left(\mathrm{MJ} / \mathrm{cm}^{2}\right)$

$\mathrm{P}$ - Lamp power $(\mathrm{W})$

PS - Polystyrene

$\mathrm{P}_{\mathrm{s}}$ - Incident power $\left(\mathrm{W} / \mathrm{cm}^{2}\right)$

$\mathrm{R}$ - Distance form UV source to the sample $(\mathrm{cm})$

$\mathrm{t}$ - time $(\mathrm{s})$

$\mathrm{UV}$ - B - Ultraviolet B radiation

$\mathrm{W}_{\mathrm{i}}$ - initial mass of the sample $(\mathrm{g})$

$\mathrm{W}_{\mathrm{o}}$ - mass of the metal cage $(\mathrm{g})$

$\mathrm{W}_{\mathrm{s}}$ - dry insoluble mass $(\mathrm{g})$

$\Delta \mathrm{Hm}$ - Heat of fusion $(\mathrm{J} / \mathrm{g})$

$\Delta \mathrm{Hm}$ ' - Heat of melting for $100 \%$ crystalline PS

\section{Introduction}

Polystyrene (PS) is one of the most consumed rigid thermoplastic polymers worldwide owing to its high refractive index, good chemical resistance, low moisture absorption, density, electrical conductivity, ease of coloring, processability, and low cost of production [1]. The versatility of PS makes it useful in various industrial applications, such as the components of machines, vehicles, electronics and appliances, as well as in refrigerators, electric motors, seats, sanitary parts, heels and soles of shoes, stationery, and disposables $[1-5]$.

In several of these applications, failure due to fatigue is caused by the application of cyclic stresses, under values below the fracture limit. Fatigue failure is observed by the formation of microscopic cracks that are nucleated at stress concentrators or beneath the material surface until catastrophic failure occurs. Additionally, when employed outdoors, the action of environmental agents on the surface of polymers can promote structural changes of a physical, chemical, and mechanical nature [6-9].

Thus, the objective of this work was to evaluate the influence of ultraviolet (UV) radiation on the mechanical behavior of PS subjected to fatigue. Macromolecular changes induced by the degradative process at different exposure times were analyzed.

\section{Materials and Methods}

The PS used in this work is an all-purpose commercial product. This as-received PS was processed by extrusion in the form of $6 \mathrm{~mm}$ thick plates. Samples with dimensions of $30 \times 30 \mathrm{~cm}$ were produced by mechanical machining of the as-received plate and were previously approved by visual inspection to ensure accordance with the technical standards.

Exposure to ultraviolet radiation (UV-B), corresponding to the UV-B wave spectrum region (290-315 nm), was performed at room temperature in a chamber of an accelerated nonmetallic aging system (Comexim 
C-UV) adapted to ASTM G154-12 [10]. Each sample face was exposed to UV radiation for 336 and $575 \mathrm{~h}$ without simulating rain and/or mist. Comexim fluorescent lamps with $40 \mathrm{~W}$ intensity were used as a source of UV radiation in the range of $280-320 \mathrm{~nm}$, with a peak seen at $313 \mathrm{~nm}$.

The incident energy in the samples was calculated using Equations 1 and 2, by employing fundamental physical relationships.

$$
\begin{gathered}
\overline{\text { Incident energy }\left(I_{e}\right)=P_{s} * t \quad(1)} \\
\overline{P_{s}=\frac{P * A_{0}}{4 \pi * R^{2}} \quad(2)}
\end{gathered}
$$

where $I_{e}$ is the value of incident energy on the sample, $P_{s}$ is the incident power on the sample, $t$ is the time of exposure to radiation, $P$ is the power of the lamp, $A_{0}$ is the surface area of the test sample exposed to radiation, and $\mathrm{R}$ is the distance from the UV source to the sample [11,12]. Table 1 presents the incident energy for both exposure times, with $R=5 \mathrm{~cm}$ and $A_{0}=900 \mathrm{~cm}^{2}$.

Table. 1: Energy incident in the samples depending on the exposure time.

\begin{tabular}{ll}
\hline Exposure time $(\mathrm{h})$ & Incident energy $\left(\mathrm{MJ} / \mathrm{cm}^{2}\right)$ \\
\hline 336 & 24.1 \\
575 & 41.2 \\
\hline
\end{tabular}

The mechanical, structural, and morphological properties of polystyrene under fatigue combined with accelerated aging were investigated by mechanical fatigue, gel permeation chromatography (GPC), gel percentage, thermogravimetric analysis (TGA), differential scanning calorimetry (DSC), and scanning electron microscopy (SEM).

The mechanical fatigue behavior was evaluated under load control (Instron universal testing machine 8874) following the ASTM-D3479 [13] standard. The experimental conditions used included a load rate of LR = 0.5 , frequency of $5 \mathrm{~Hz}$ at $25^{\circ} \mathrm{C}$, and $50 \%$ relative humidity. For each group, five samples of type 1 ASTM-D638 [14] were tested.

The microhardness test was carried out using a Shimadzu Microdurometer with a pyramidal penetrator containing a square diamond base with an angle of $136^{\circ}$ in each of the specimens to assess the surface hardness, according to the ASTM E384-11 standard testing method [15]. A load of $0.05 \mathrm{kgf}$ was used for 30 s.

GPC was used to determine the weight-average molecular weight $(\mathrm{Mw})$ and polydispersity $(\mathrm{Mw} / \mathrm{Mn})$ of the samples, before and after UV irradiation on the investigated times. These GPC tests were performed on a Shimadzu chromatography system (RID 20A) at $25^{\circ} \mathrm{C}$ using PA-grade chloroform as both the solvent and mobile phase, at a flow rate of $1 \mathrm{~mL} / \mathrm{min}$. Mass standards of monodisperse polystyrene were used to calibrate the GPC system.

The percentage of gel produced by the radiation action, before and after exposure to UV-B, was determined by extracting the non-crosslinked fraction in a Soxhlet extractor following the ASTM D-2765 standard testing method [16]. Decahydronaphthalene P.A. was used as a solvent for $6 \mathrm{~h}$ under reflux $\left(189-192{ }^{\circ} \mathrm{C}\right)$ at a rate of 40 drops per min. The insoluble fraction was dried at $110{ }^{\circ} \mathrm{C}$ for $12 \mathrm{~h}$ until the mass remained constant. The degree of crosslinking was estimated using Equation 3,

$$
\overline{\text { Degree of cross }- \text { linking }(\%)=\frac{W_{s}-W_{0}}{W_{i}-W_{0}} * 100 \quad(3)}
$$


where $\mathrm{W}_{\mathrm{s}}$ is the dry insoluble sample mass $(\mathrm{g}), \mathrm{W}_{\mathrm{i}}$ is the initial mass of the sample $(\mathrm{g})$, and $\mathrm{W}_{\mathrm{o}}$ is the mass of the metal cage.

TGA tests of the surface region of the samples were conducted (Netzsch model TG 209F1 Libra) under a nitrogen atmosphere at a flow rate of $30 \mathrm{~mL} / \mathrm{min}$ and heating rate of $10{ }^{\circ} \mathrm{C} / \mathrm{min}$, from 30 to $800{ }^{\circ} \mathrm{C}$. The inflection point of the thermogravimetric curve was considered as the onset of decomposition.

DSC tests were conducted using an Indian calibrated Netzsch model DSC 404 F1 Pegasus, which was coupled to a computerized analysis system as per the ASTM D3417 standard testing method [17]. Samples were collected from the surface region for each testing condition, weighing between 0.9 and $1.1 \mathrm{mg}$, and placed in aluminum crucibles. The samples were subjected to a double heating/cooling cycle ranging from $-100{ }^{\circ} \mathrm{C}$ to $300{ }^{\circ} \mathrm{C}$ at a heating rate of $10{ }^{\circ} \mathrm{C} / \mathrm{min}$ under a nitrogen atmosphere at a flow rate of $20 \mathrm{~mL} / \mathrm{min}$. Under these conditions, it was possible to calculate the degree of crystallinity of PS before and after radiation exposure using Equation 4.

$$
\begin{aligned}
& \hline \text { Degree of crystallinity }(\%)=\frac{H_{m}}{H_{m^{\prime}}} * 100 \quad(4) \\
& \hline
\end{aligned}
$$

where $\Delta ?$ ? is the heat of fusion of each sample $(\mathrm{J} / \mathrm{g})$ and $\Delta ?$ ?' is the heat of melting for $100 \%$ crystalline polystyrene, equal to $86 \mathrm{~J} / \mathrm{g}[18]$.

The PS failure surface analysis was performed by observing the fracture cross-section after the test. This surface was examined using SEM (Quanta FEG250, FEI). The samples were previously coated with platinum in a vacuum chamber.

\section{Results and Discussion}

The investigation of the mechanical fatigue behavior of PS was carried out by maintaining the stress amplitude between 7.5-13 Mpa, at room temperature until material failure occurred, as observed in Figure 1.A. Figure 1.B shows the deformation response of the applied load.

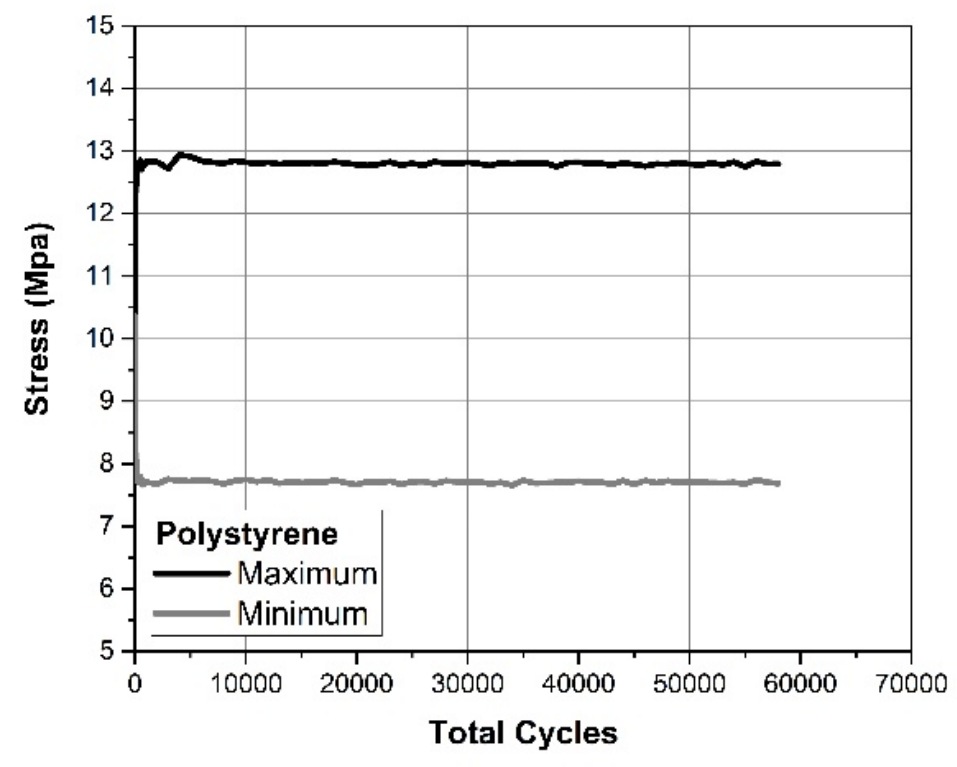




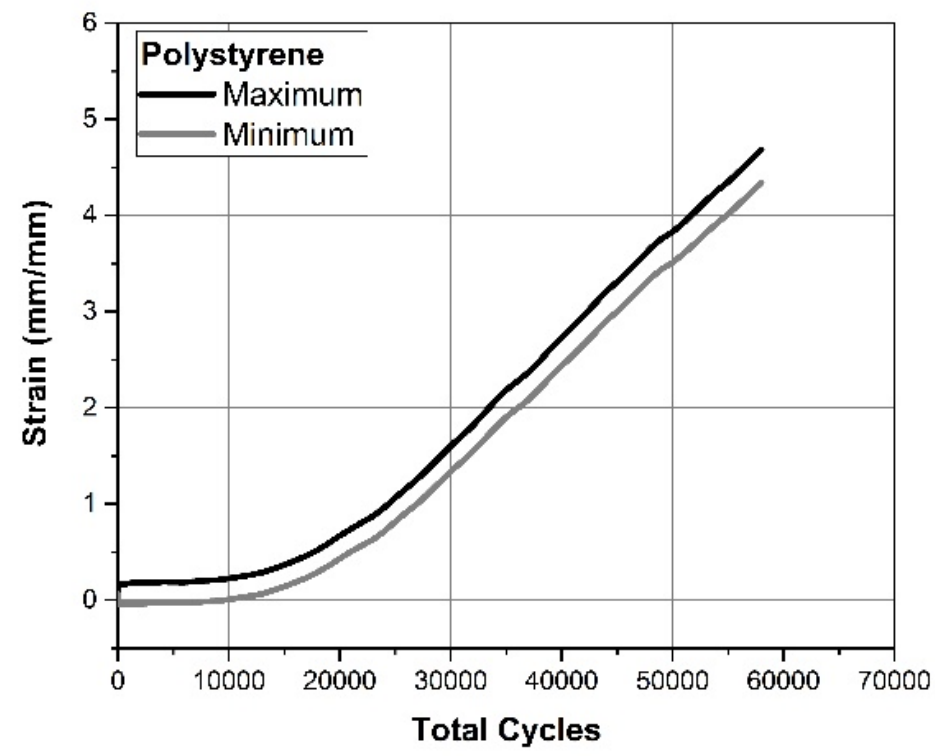

$\overline{(\mathrm{A}) \quad(\mathrm{B})}$

Figure 1: (A) Stress x number of cycles, (B) Strain x number of cycles, both of the fatigue behavior presented by polystyrene.

It is noted that the graph of the number of cycles vs. stress shows a constant behavior until fracture occurs, which was expected. However, the same behavior was not observed in the response to tension. After the $25 \times 10^{3}$ cycle, PS acts as a viscoelastic material, and a softening process began that may be associated with localized heating. This is a result of the frequency employed and the low thermal conductivity of the PS. However, no significant temperature variation $\left( \pm 2{ }^{\circ} \mathrm{C}\right)$ was observed during equipment testing.

Many products used in industry are usually influenced by physical and chemical conditions as well as by fatigue stress. Thus, conditions of accelerated aging combined with fatigue stress were imposed on the PS samples in order to discuss the relationship and the influence of both on the material. Table 2 shows the effect of UV-B on the fatigue behavior of the PS, under a constant load and amplitude previously presented until total failure of the samples occurs.

Table 2: Results obtained in behavior under fatigue for all conditions.

\begin{tabular}{llll}
\hline Exposure time $(\mathrm{h})$ & Total Cycles in break & Softening Cycle (onset) & $\begin{array}{l}\text { Softening Deformation } \\
\text { (onset) }\end{array}$ \\
\hline 0 & $44000 \pm 10360$ & $23167 \pm 3276$ & $0.47 \pm 0.45$ \\
336 & $24500 \pm 11846$ & $17597 \pm 12495$ & $0.20 \pm 0.06$ \\
575 & $21500 \pm 10408$ & $17147 \pm 9061$ & $0.15 \pm 0.08$ \\
\hline
\end{tabular}

The average values obtained in this study clearly show that the cyclic stresses and the exposure to UV significantly influenced the mechanical properties of PS, presenting a relative dispersion characteristic when 
dealing with fatigue. Thus, the useful life (number of cycles to failure) of the irradiated PS was less than that of the as-received PS, with a reduction of $45 \%$ for $336 \mathrm{~h}$ of exposure, corresponding to an energy of $24.1 \mathrm{MJ} / \mathrm{cm}^{2}$. A reduction of $51 \%$ for $575 \mathrm{~h}$ of exposure was observed, which corresponds to almost twice the energy of the previous result, $41.2 \mathrm{MJ} / \mathrm{cm}^{2}$. This indicates a weakening of the irradiated material, as highlighted in Figure 2.A.

Cyclic loading under tension control does not have a constant strain range. In this study, it was observed that the material resistance to cyclic deformation increases with the fatigue process, in addition to presenting an exponential behavior. Therefore, in order to quantitatively evaluate the behavior of the material regarding softening, the relationships between the onset of this phenomenon with respect to the number of cycles (Figure 2.B) and cyclic deformation (Figure 2.C), both depending on the exposure time, were performed and noted during the test.

The results obtained in the tests show that the softening process occurs after half the useful life of the material with $53 \%$ for PS under fatigue, $72 \%$ for PS fatigued and exposed to radiation for $336 \mathrm{~h}$, and $80 \%$ for PS fatigued and exposed to radiation for $575 \mathrm{~h}$.

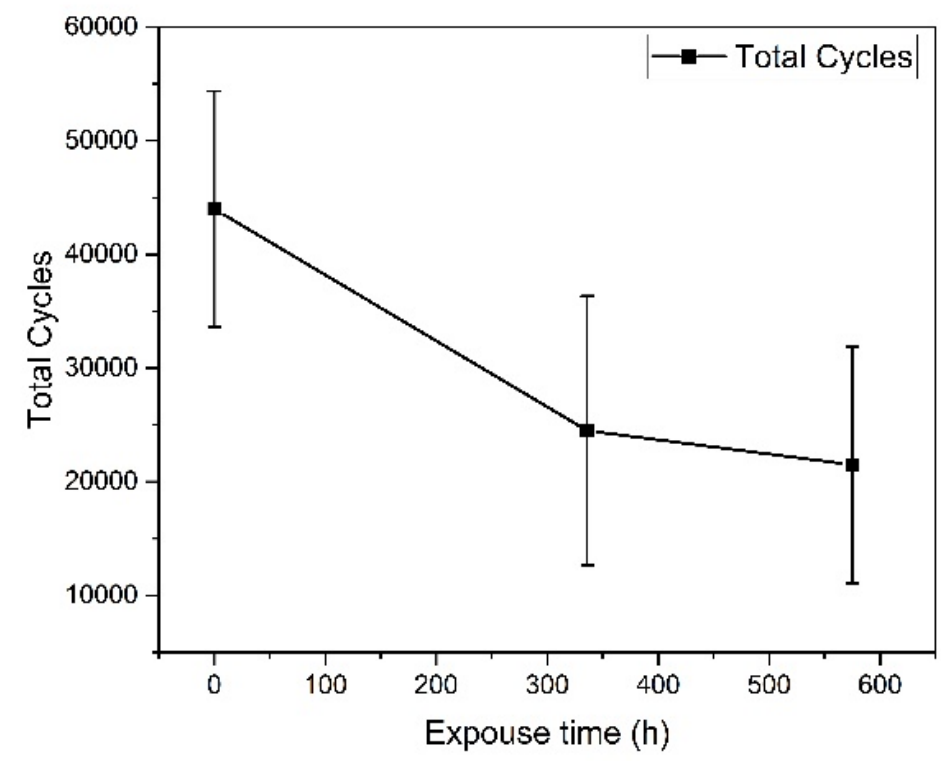




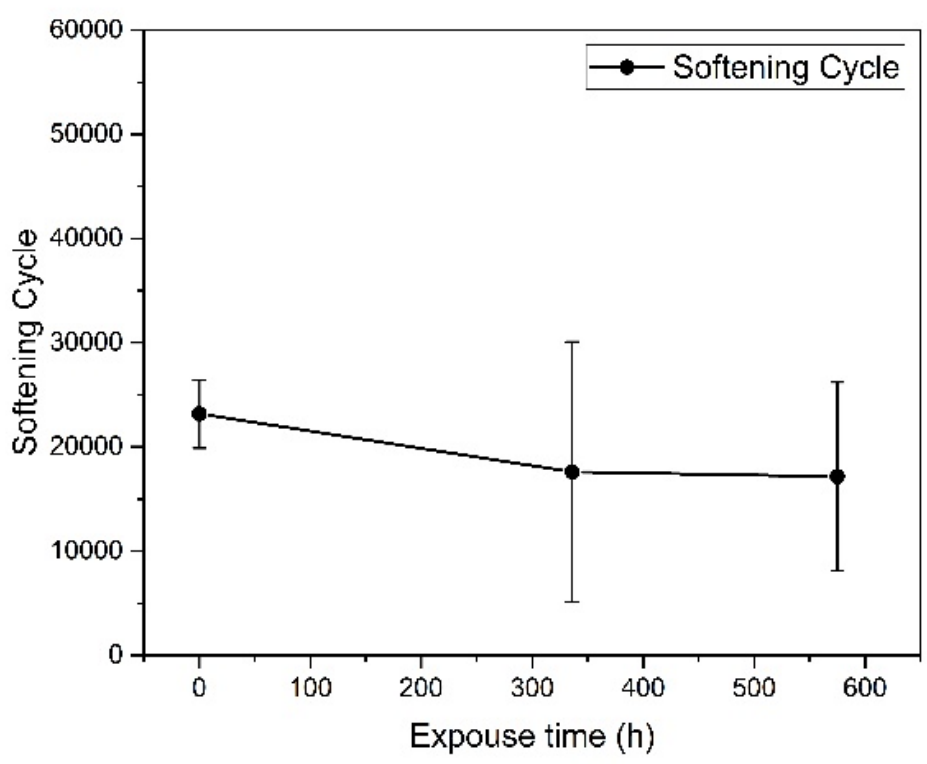

(A) (B)

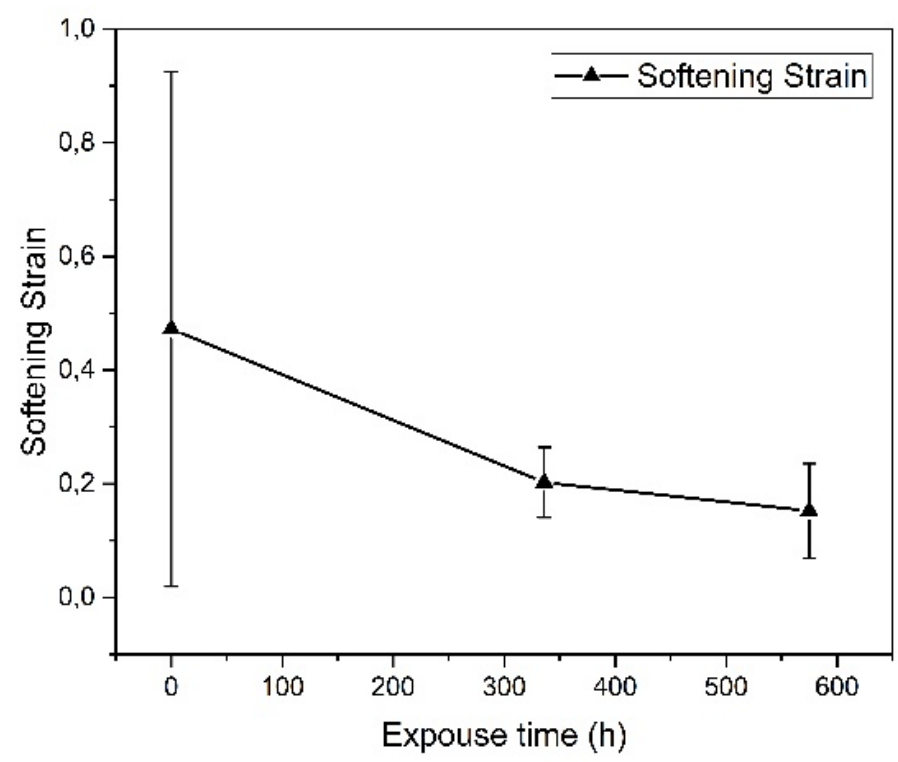




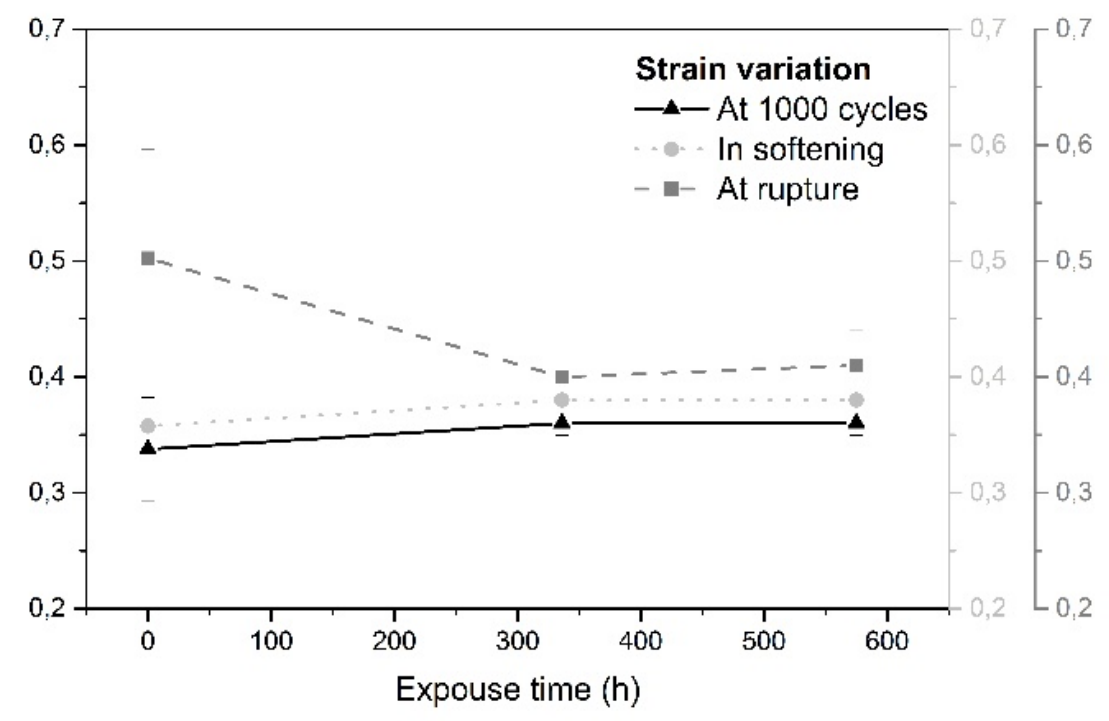

(C) (D)

Figure 2: Results of behavior under fatigue; (A) total cycles $\mathrm{x}$ expose time, (B) softening cycles $\mathrm{x}$ expose time, (C) softening strain $\mathrm{x}$ expose time, (D) strain variation.

In addition, the lifetime of the exposure condition of $575 \mathrm{~h}$ indicated a progressive upward trend but was still less than that of non-irradiated material. This result is possibly related to the surface conditions of the specimens and the depth of the degraded layer, which were not measured in this study.

The surface hardness of the samples was characterized using a Vickers meter; the results are presented in Table 3. The sample data exhibited a normal and homogeneous distribution along the surface of the specimens. The results of this analysis showed that there was a difference in the conditions evaluated. The mean hardness for all the irradiated samples of PS evaluated was significantly greater than that of the "as received" PS. However, the irradiated groups showed statistically similar values, suggesting a saturation of the superficial degradation of this material.

Table 3: Average values of Vickers microhardness.

\begin{tabular}{ll}
\hline Exposure time $(\mathrm{h})$ & Microhardness (HV) \\
\hline 0 & $9,90 \pm 0,93$ \\
336 & $22,86 \pm 0,53$ \\
575 & $23,36 \pm 0,38$ \\
\hline
\end{tabular}

Chain reactions of chemical decomposition forming free radicals can promote the formation of micro-cracks and/or surface hardening. The orientation of the phases would be beneficial to the increase in the mechanical properties. In this way, the molecular weight, gel content, and thermal analyses were investigated.

The average weight molecular weight (??) and polydispersion (??/??), obtained through the surface region 
GPC curves, before and after UV irradiation, are shown in Figure 3. A tendency of molecular weight reduction was observed, as a variation of polydispersion in the investigated times. This behavior was also reported by other researchers in distinct works on degradation process [19].

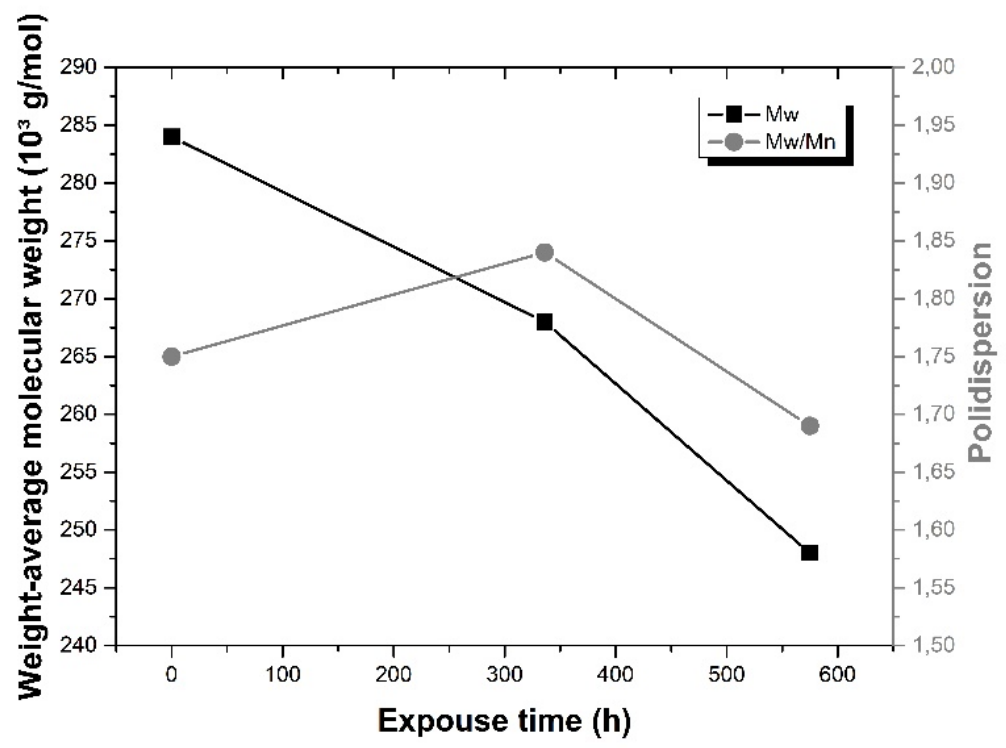

Figure 3: Molecular weight and polydispersion for all exposure times.

The reduction in the mass produced with increasing exposure times of 336 and $575 \mathrm{~h}$ was $6 \%$ and $13 \%$, respectively. There was no stability trend, suggesting that longer exposure times would imply smaller molecular masses [19-21]. The profile of the curves obtained suggests the occurrence of oxygen diffusion and the attenuation of UV radiation on the surface region of the investigated PS, as a consequence of heterogeneous degradation and lack of mass uniformity $[22,23]$.

The gel percentages for all conditions are shown in Table 4. No significant increase was found in the degree of crosslinking after UV irradiation as compared to the as-received PS. A maximum of $1 \%$ increase at an irradiated dose of $575 \mathrm{~h}$ was observed when compared to the non-irradiated material [24, 25].

Table 4. Degree of cross-linking of PS, before and after UV radiation.

\begin{tabular}{ll}
\hline Expouse time $(\mathrm{h})$ & Degree of cross-linking (\%) \\
\hline 0 & $0,2 \pm 0,1$ \\
336 & $0,3 \pm 0,1$ \\
575 & $0,4 \pm 0,1$ \\
\hline
\end{tabular}

Table 5 presents the results obtained by TGA and DSC thermal analysis of PS before and after exposure to UV radiation. Figure 4 brings the complete results for the DSC analysis. A similarity between the onset decomposition temperatures of the irradiated materials was identified when compared to the as-received PS, guaranteeing thermal stability under the studied conditions. However, the degree of crystallinity increased considerably for the UV-irradiated materials, suggesting the occurrence of rearrangement of the macromolecules that were cleaved in the amorphous region. This corroborates the chromatography and gel content results that were obtained $[26,27]$. 
Table 5. Thermal analysis (TGA / DSC) results obtained for all conditions. Complete results are shown in Figure 4.

\begin{tabular}{llll}
\hline Exposure time $(\mathrm{h})$ & Decomposition temperature $\left({ }^{\circ} \mathrm{C}\right)$ onset & Decomposition temperature $\left({ }^{\circ} \mathrm{C}\right)$ midset & Glass transition ( \\
\hline 0 & 392.97 & 421 & 99.2 \\
336 & 398.33 & 424 & 99.4 \\
575 & 399.67 & 422 & 98.4 \\
\hline
\end{tabular}

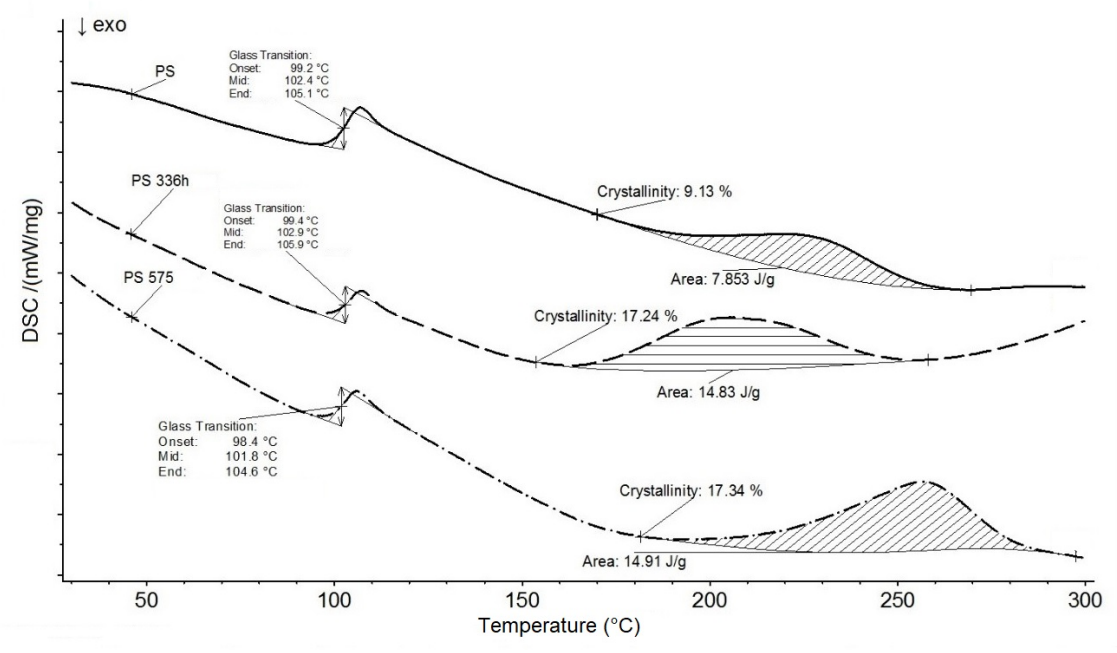

Figure 4: DSC Results obtained for all conditions.

With respect to the fatigue results, it should be noted that as the time of exposure to UV radiation increases, the number of cycles changes, probably due to the surface degradation of the samples. This behavior results from the embrittlement of irradiated PS due to its high crystallinity and reduction of molecular weight produced by the degradation caused by UV radiation [20].

SEM micrographs of the fracture surfaces of the fatigue-tested specimens are shown in Figure 5. According to the equivalent stress amplitude levels, in which all evaluation groups were subjected, the PS in the nonirradiated condition supports a much higher number of cycles than the UV degraded material. All samples exposed to UV radiation displayed a predominantly brittle fracture, indicating that the main failure mode for the mechanical fatigue mechanism. However, when analyzing the fracture surface of the non-irradiated PS, regions of brittle behavior and ductile appearance are observed, which is typical of mixed fractures [28].

The brittleness of the degraded surface, confirmed by the reduction in molecular mass, is evidenced in the micrographs of the UV degraded groups. In addition, the progressive recovery of resistance observed in the fatigue test is noteworthy because the fracture surface of the PS 575 UV group has ductile regions. These regions could be associated with molecular chain movements such as rotation and stretching. 


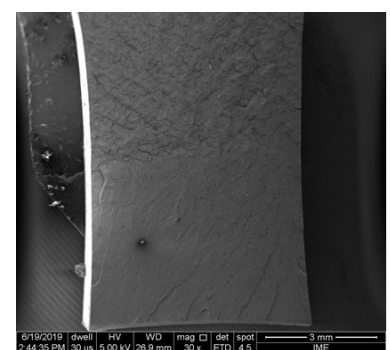

(A)

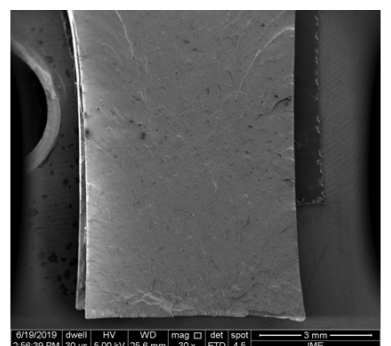

(B)

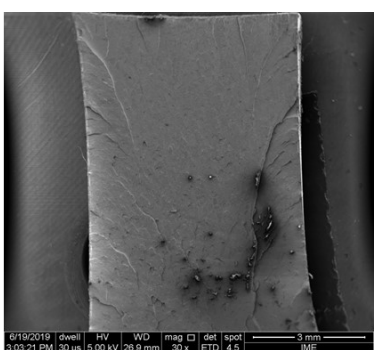

(C)

Figure 5: SEM photomicrograph of fracture surface: a) 0h exposure, b) 336h exposure and c) 575h exposure.

\section{Conclusions}

The evaluation of the experimental results obtained along with the information contained in the literature indicates that PS when exposed to UV-B radiation in an oxidizing atmosphere exhibits macromolecular modification that influences its mechanical properties.

- The UV degradation of PS occurs preferably by cleavage of the molecular chains, as indicated by chromatography and gel content. No crosslinking is produced; however, there is a reduction in molecular mass as a function of exposure time in the surface region.

- Exposure to UV radiation at exposure times of 336 and $575 \mathrm{~h}$ was not sufficient to change the decomposition temperature of PS, as this remained virtually unchanged. However, significant changes in the degree of crystallinity were obtained and attributed to a possible crystalline rearrangement after cleavage of the chains.

- Regarding the mechanical behavior of PS, UV radiation alters its mechanical fatigue, resulting in changes in specimen properties, such as the reduction in the number of cycles accumulated until fracture. This behavior is possibly related to the surface conditions of the specimen and its degradation thickness.

- Relating the fracture surface characteristics, it appears to be a mixture of brittle cleavage of molecular chains with ductile rotation and stretching of these chains.

\section{Acknowledgments}

The authors would like to thank Wiley Services for English language editing. The authors also thank the Brazilian support agencies CAPES, CNPq, and FAPERJ for the financing, the Materials Laboratory of the Brazilian Army Technology Center (CTEx).

\section{Conflicts of interest}

The authors declare no conflicts of interest.

\section{References}

1. SIMPESC. SIMPESC - POLYSTYRENE: attention to numbers (In Portuguese), (2015). Available at: http://www.simpesc.org.br/2015/03/poliestireno-atencao-aos-numeros/. (Accessed: 3rd May 2018).

2. Brandrup J, Immergut EH, Grulke EA. Polymer Handbook. US: John Wiley \& Sons, Ltd; 1999.

3. Grassi VG, Madalena M, Forte C, Dal Pizzol MF. Morphological aspects and structure-properties relationship of high impact polystyrene (in Portuguese). Sci Tech Poly . 2001; 11: 158-168. 
4. Euclydes CCF. Polystyrene: The Material And Its Transformation(In Portuguese). Brazil: Brothers Semerano; 1995.

5. Baltá-Calleja FJ, Cagiao ME, Adhikari R, Michler GH. Relating microhardness to morphology in styrene/butadiene block copolymer/polystyrene blends. DOI:10.1016/j.polymer.2003.10.089.

6. De Paoli M. Polymer Degradation and Stabilization (In Portuguese). Brazil: Chemkeys; 2008.

7. Ward IM, Sweeney J. A Introduction To The Mechanical Properties Of Solid Polymers . US: John Wiley \& Sons, Ltd.; 2004.

8. Riddell MN. A guide to better testing of plastics. Plast. Eng.1974; 30: 71-78.

9. Nielsen L. Mechanical Properties Of Polymers And Composites . US: M.Dekker; 1994.

10. ASTM G 154-16. Standard Practice for Operating Fluorescent Ultraviolet (UV) Lamp Apparatus for Exposure of Nonmetallic Materials. Annu. B. ASTM Stand. (2016).

11. Becerra, A. F. C. \& D'Almeida, J. R. M. UV effects on the tensile and creep behaviour of HDPE. Polym Polym Compos. 2017; 25: 327-332.

12. Klein, M. V \& Furtak, T. E. Optics . US:Jonh Wiley and Sons; 1986.

13. ASTM D 3479. Standard Test Method for Tension-Tension Fatigue of Polymer Matrix Composite Materials. Annu. B. ASTM Stand. (2016).

14. ASTM D 638-14. Standard Test Method for Plastic Tensile Properties. Annu. B. ASTM Stand. (2014).

15. ASTM E384-17, Standard Test Method for Microindentation Hardness of Materials, Annu. B. ASTM Stand. (2017).

16. ASTM D 2765-16. Standard Test Methods for Determination of Gel Content and Swelling Ratio of Cross-linked Ethylene Plastics. Annu. B. ASTM Stand. (2016). DOI:10.1520/D2765-16.

17. ASTM D 3417-99. Standard Test Method for Differential Exploratory Calorimetry (DSC) Polymer Fusion and Crystallization Enthalpies. Annu. B. ASTM Stand. (1999). DOI:10.1520/D3417-99.

18. Lucas EF, Soares BG, Monteiro EEC. Polymer Characterization: Molecular Weight Determination and Thermal Analysis (In Portuguese). E-papers, 2001.

19. Remili CMK. Photo-oxidation of polystyrene/clay nanocomposites under accelerated UV exposure: Effect of the structure and molecular weight.J Appl Polym Sci . 2019; 112: 2868-2875.

20. Yousif E, Haddad R. Photodegradation and photostabilization of polymers, especially polystyrene: Review. Springerplus . 2013; 2: 1-32.

21. Lambert S, Wagner M. Characterisation of nanoplastics during the degradation of polystyrene. Chemosphere. 2016; 145, p. 265-268.

22. Girois SLA. Molecular weight changes during the photooxidation of isotactic polypropylene. Polym. Degrad. Stab . 1996; 51: 125-132.

23. Babaghayou MI. Photodegradation characterization and heterogeneity evaluation of exposure and unexposed faces os stabilized and unstabilized LDPE films. Mater Des . 2016; 111: 279-290.

24. Lee KH, Kim HY, La YM, Lee DR, Sung NH. Influence of a mixing solvent with tetrahydrofuran and N, N-dimethylformamide on electrospun poly(vinyl chloride) nonwoven mats. J Polym Sci Part B Polym Phys . 2002; 40: 2259-2268.

25. David C, Baeyens D. VolantStatistical theories of main chain scission and crosslinking of polymersapplication to the photolysis and radiolysis of polystyrene studied by gel permeation chromatography.Eur. Polym. J . 1978; 14: 29-38.

26. Fernandes LL, Freitas CA, Demarquette NR, Fechine GJM. Study of the effect of the polypropylene type on the photodegradation of the high impact polypropylene/polystyrene blend (In Portuguese).Polímeros . 2012; 22: 61-68.

27. Zhang H, Shi M. Effects of Sunshine UV Irradiation on the Tensile Properties and Structure of Ultrahigh Molecular Weight Polyethylene Fiber. J Appl Polym Sci. 2003; 89.

28. Celina MDKO. FTIR emission spectroscopy applied to polymer degradation. Polym Degrad Stab . 1997; 58: 15-31.

Availability of Data: The data that support the findings of this study are available from the corresponding author upon reasonable request. 
Statement of Contribution: K.G.C. Monsores, A.O. Silva and R.P. Weber processed the experimental data, performed the analysis, drafted the manuscript and designed the figures. S.S. Oliveira and P.F. Filho performed the measurements (TGA/DSC). L.G. Simão manufactured the samples and characterized them (microhardness). E.A. de Carvalho performed the Fatigue characterization. E.A. de Carvalho and S.N. Monteiro. aided in interpreting the results and worked on the manuscript. All authors discussed the results and commented on the manuscript. 